NBER WORKING PAPER SERIES

\title{
DAYS OF HAZE: ENVIRONMENTAL INFORMATION DISCLOSURE AND INTERTEMPORAL AVOIDANCE BEHAVIOR
}

Joshua Graff Zivin

Matthew Neidell

Working Paper 14271

http://www.nber.org/papers/w14271

\author{
NATIONAL BUREAU OF ECONOMIC RESEARCH \\ 1050 Massachusetts Avenue \\ Cambridge, MA 02138
}

August 2008

The views expressed herein are those of the author(s) and do not necessarily reflect the views of the National Bureau of Economic Research.

NBER working papers are circulated for discussion and comment purposes. They have not been peerreviewed or been subject to the review by the NBER Board of Directors that accompanies official NBER publications.

(C) 2008 by Joshua Graff Zivin and Matthew Neidell. All rights reserved. Short sections of text, not to exceed two paragraphs, may be quoted without explicit permission provided that full credit, including (C) notice, is given to the source. 
Days of Haze: Environmental Information Disclosure and Intertemporal Avoidance Behavior Joshua Graff Zivin and Matthew Neidell

NBER Working Paper No. 14271

August 2008

JEL No. D80,I18,Q53

\begin{abstract}
$\underline{\text { ABSTRACT }}$
In this paper, we investigate the dynamics of informational regulatory approaches by analyzing the impact of smog alerts issued on consecutive days on discretionary outdoor activities in Southern California. Short-run adjustments to transitory risk entail costs that are likely to influence the set of evasive actions pursued by those at risk. Our results confirm that the cost of intertemporally substituting activities is increasing over time: when alerts are issued on two successive days, any response on the first day has largely disappeared by the second day. Small reprieves from alerts, however, reset these costs. Our findings imply that a time-varying decision rule that accounts for multiple day air quality forecasts may improve social welfare.
\end{abstract}

\author{
Joshua Graff Zivin \\ Department of Health Policy and Management \\ Columbia University \\ 600 West 168th Street, Room 608 \\ New York, NY 10032 \\ and NBER \\ jz126@columbia.edu \\ Matthew Neidell \\ Department of Health Policy and Management \\ Columbia University \\ $600 \mathrm{~W}$ 168th Street, 6th Floor \\ New York, NY 10032 \\ and NBER \\ mn2191@columbia.edu
}




\section{Introduction}

Informational approaches to regulation have emerged as an important tool in the health and environmental policymakers' arsenal. The US Environmental Protection Agency requires the public reporting of toxic chemical emissions from industrial facilities in the Toxics Release Inventory. Massive information campaigns have been waged to warn susceptible consumers about the risks of consuming fish contaminated with high levels of mercury. Warning systems in many cities around the world inform citizens when air quality falls below a certain targeted level. The principal supposition in each of these cases is that individuals appropriately adjust their behavior in response to this information.

Both long-run adjustments to permanent risk and short-run adjustments to transitory risk entail costs that are likely to influence the set of evasive actions pursued by those at risk. For episodic risks, such as those associated with poor air quality, contaminated drinking water, or tainted food, the costs of responding should, in part, depend on the frequency with which warnings are issued. For example, imagine a poor air quality spell that lasts for ten consecutive days. The intertemporal costs from forgoing one day of outdoor time on the first day of the warning episode are likely to be much lower than the costs on the tenth day of that episode. ${ }^{1}$ While a growing body of evidence suggests that individuals engage in protective actions in response to announced risks $^{2}$, very little has been done to directly examine the role of intertemporal avoidance behavior. Since climate change is expected to increase the frequency and duration of

\footnotetext{
${ }^{1}$ Similarly, the costs of eliminating tomatoes from your diet during a salmonella outbreak may be quite low for the first few days, but as one exhausts their repertoire of tomato-less recipes the costs of avoidance become steadily higher.

${ }^{2}$ See, for example, Ahituv et al. (1996), Bresnahan et al. (1997), Jin and Leslie (2003), Mullahy (1999), Shimshack et al. (2007), Philipson (1996), Smith and Johnson (1988), Viscusi et al. (1986).
} 
such episodic events, understanding these dynamic responses is of growing policy importance.

In this paper, we investigate the dynamics of informational regulatory approaches by analyzing the impact of smog alerts issued on consecutive days on outdoor activities in Southern California. California state law requires a stage 1 air quality episode warning ("smog alert") when ground-level ozone ${ }^{3}$, a pollutant linked to numerous health conditions, such as asthma, pneumonia, and bronchitis, is expected to exceed a particular level. Southern California provides an ideal setting to examine this research question because the notoriously poor air quality results in frequent smog alerts that are broadly disseminated across various media channels. Moreover, previous work has demonstrated that individuals respond to single-day alerts, suggesting that people value the information content provided by the warning system (Neidell (forthcoming)). Our goal is to expand that analysis by exploring the behavioral dynamics of consecutive day alerts and thus shed light on the role of private mitigation costs under this regulatory approach.

Since a smog alert is issued if the underlying air quality index exceeds a particular threshold, we identify the effect of smog alerts using a regression discontinuity design. The threshold is not predicated on air quality levels associated with a non-linear change in the health of those exposed, so days just at or above this threshold can be viewed as otherwise equivalent to days just below it, and any difference in outdoor activities at the threshold can be attributed to the alert. Frequent ozone forecasting mistakes also strengthen this design, as days that may appear somewhat different ex-ante often end up identical ex-post. As a measure of outdoor activities, we use daily attendance from 1989

\footnotetext{
${ }^{3}$ Ground level ozone is distinct from stratospheric ozone (the "ozone layer"), which affects the amount of ultra-violet radiation that reaches the earth.
} 
to 1997 at two major outdoor facilities in Southern California -- the Los Angeles Zoo and the Griffith Park Observatory.

Our results demonstrate that when an alert is issued on one day only, attendance at the Zoo and Observatory decreases by a statistically significant $15 \%$ and $8 \%$, respectively. The response to an alert on the second consecutive day, however, falls to a statistically insignificant $5 \%$ and $0 \%$, respectively. Furthermore, the response at the Zoo drops to zero when an alert is issued for three consecutive days. When we examine the response for more vulnerable groups, such as children and the elderly, we reassuringly find a larger response to warnings, but still find a decreased response on the second day, albeit a less dramatic drop than that found for others. Interestingly, a one-day reprieve from smog alerts is sufficient for responses to rebound in magnitude to the first day response at the Zoo. Together, these results confirm that the cost of intertemporally substituting activities is increasing over time, but that small reprieves reset these costs.

Since the recreational activities we examine are more discretionary than other types of outdoor activities, our empirical analysis provides a conservative test for diminishing responses over time. That is, if individuals are unwilling to bear the costs of avoiding the zoo for the second day in a row, it seems very likely that individuals deciding about less discretionary activities, such as agricultural harvesting, will not respond to an alert on the second consecutive day because the costs of avoiding this activity are likely to be even higher. ${ }^{4}$

Our findings imply that a time-varying decision rule that accounts for multiple day air quality forecasts may be optimal. One possibility would be to publicly

\footnotetext{
${ }^{4}$ For less discretionary outdoor activities, there may also be no response to an alert on the first day. If interventions are justifiable for these activities, informational approaches to regulation will clearly be suboptimal.
} 
disseminate multi-day smog alert forecasts to allow individuals to make more informed decisions about re-organizing their schedules. Since people respond to alerts and not the underlying index (Neidell (forthcoming)), however, a more efficient policy may be to issue an alert on the worse of the two days. ${ }^{5}$ If the first day has worse air quality, the welfare impacts are the same under the status quo or the dynamic decision rule. But if the second day has worse air quality, the dynamic decision rule improves health outcomes relative to the status quo but at the same cost. If such a policy is impractical, the response dynamics suggest that an adjustment to the alert threshold could lead to second-best welfare improvements.

The rest of the paper proceeds as follows. The next section provides background information on air quality and smog alerts. Section 3 describes the data and section 4 presents the empirical strategy. Section 5 shows the results and section 6 concludes.

\section{Background Information on Air Quality}

Human exposure to ozone irritates lung airways and has been linked to many short-run health conditions, including asthma. Symptoms can occur in as quickly as one hour of exposure, (U.S. EPA (2006)), suggesting an important role for interventions that can alter short-run exposure. As a result, ground-level ozone is a criteria pollutant regulated under the Clean Air Acts, with ambient air quality standards for both 1-hour and 8-hour concentrations of ozone.

The process leading to ozone formation makes it highly predictable and relatively straightforward to avoid. Ozone is formed from interactions of nitrogen oxides and volatile organic compounds in the presence of heat and sunlight. Ozone formation also

\footnotetext{
${ }^{5}$ Responding to alerts and not levels is consistent with rational optimizing behavior if the costs of acquiring the index are sufficiently high, though we view this as unlikely since it is readily available in the newspaper.
} 
increases with solar radiation. Because of this process, ozone levels tend to peak in the summer and during the hottest times of the day, allowing future levels to be predicted using weather forecasts. Since ozone breaks down rapidly indoors where there is less heat and/or sunlight, ${ }^{6}$ people can limit exposure by going indoors.

To provide local air quality information to the public, the U.S. Environmental Protection Agency developed a uniform system to measure air quality levels for the major pollutants regulated under the Clean Air Act. The pollutant standards index (PSI), renamed the Air Quality Index in 1999, ranges from 0-500 and is indexed so that a value of 100 corresponds to the National Ambient Air Quality Standards. ${ }^{7}$ This index is then broken down into categories as follows: 0-50 good; 51-100 moderate; 101-200 unhealthful; 201-275 very unhealthful; and 275+ hazardous. In order to provide ample notification for the public to react, the PSI is typically forecast one day in advance. Cities with more than 350,000 residents are required to report this information (U.S. EPA (1999)), usually found in the weather section of the local newspaper.

In addition to the federal rules governing ozone forecasts, California state law requires an air quality episode to be declared when ozone is forecast to equal or exceed 0.20 parts per million, the equivalent to 200 on the PSI. ${ }^{8}$ Since air quality episodes have only been issued for ozone, and ozone is a significant contributor to urban smog, these episodes are typically referred to as "smog alerts." Smog alerts are much more widely disseminated than the PSI; they are announced on both television and radio. When an

\footnotetext{
${ }^{6}$ For empirical evidence on the low correlation between indoor and outdoor ozone, see Chang et al. (2000).

${ }^{7}$ The AQI includes two new criteria air pollutants, 8-hour ozone and PM 2.5, as well as a new category, "unhealthy for vulnerable groups" (151-200). Given the timeframe of this study, we rely on the PSI for our empirical analysis.

${ }^{8}$ Additionally, a stage II air quality episode is issued when the ozone forecast exceeds 250 PSI or 0.30 parts per million, but this only occurred once over the time period studied.
} 
alert occurs, susceptible members of the population, including children, the elderly, and those with a history of respiratory illness, are encouraged to remain indoors and shift outdoor activities to night time. All other members of the population are advised to avoid rigorous outdoor activity during daylight hours. In addition, schools are directly contacted and advised to eliminate outdoor activities, such as physical education classes, recess, and sports practices.

The South Coast Air Quality Management District (SCAQMD) is the agency responsible for providing air quality forecasts and issuing smog alerts for Southern California. Given the wide geographic range covered by $\mathrm{SCAQMD}^{9}$ and the considerable spatial variation in ozone levels within this region, 38 distinct forecasts are created for each of the source receptor areas (SRAs) within SCAQMD. Air quality forecasts are produced by noon the day before in order to leave enough time to disseminate the information. SCAQMD staff contact a set list of recipients, including local schools and newspapers, when an alert is issued. An aggregate version of this information is further circulated through local media. The Los Angeles Times, for example, limits air quality forecasts to 10 air monitoring areas (AMAs) in SCAQMD by focusing on the maximum forecasted value of the SRAs within an AMA.

Given the reporting process and the factors believed to affect ozone formation, the model used for issuing an alert can be summarized as:

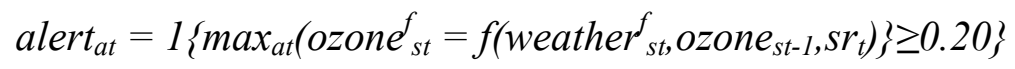

where the subscripts $a$, $s$ and $t$ indicate AMA, SRA, and date, respectively, $s r$ is solar radiation, and $1\{\bullet\}$ is an indicator function equal to 1 when the forecasted ozone exceeds

\footnotetext{
${ }^{9}$ SCAQMD covers all of Orange County and the most populated parts of Los Angeles, Riverside, and San Bernardino Counties.
} 
0.20 part per million and 0 otherwise. Alerts for ozone are only issued from March through October, compatible with the seasonal patterns of ozone.

\section{Data}

\section{$\underline{\text { A. Outdoor activities }}$}

As mentioned earlier, we use daily aggregate measures of attendance at two outdoor facilities -- the Los Angeles Zoo and Botanical Gardens ("Zoo") and Griffith Park Observatory ("Observatory") -- within the boundaries of the SCAQMD as our measure of time spent outdoors. Although focusing on two specific facilities limits the external validity of our analysis, these data provide several advantages over alternatives such as time use surveys. First, because they are administrative data, they are likely to be free of recall errors that arise in survey data. Second, the exact dates are available in the attendance data, which is critical for our regression discontinuity design. Lastly, and perhaps most importantly, these data are available over a long period of time in which there is substantial variation in ozone levels, forecasts, and smog alerts. Descriptive statistics for each are shown in Table 1.

The attendance data used in this paper span the period 1989-1997, but are collected in a slightly different manner at each location. The Zoo charges an admission fee, with the register linked to an automated system that tracks attendance. Attendance at the Observatory is free-of-charge, with attendance entered by hand in daily log files based on figures recorded from two turnstiles that people use to enter the grounds.

The Zoo, because it charges varying admission fees, also allows us to identify attendance by age groups, including adults, children under 2, children aged 2-12, and seniors aged 62 and up. These distinctions are especially useful since they allow us to 
test for a differential effect of warnings among children and the elderly, both of whom are more susceptible to the ill-effects of ozone on average. ${ }^{10,11}$ The Zoo data also allows us to identify attendance by Greater Los Angeles Zoo Association (GLAZA) members. ${ }^{12}$ Since GLAZA members are typically local residents who may find it easier to switch activities on high ozone days, we will focus on this group to further examine how the ‘costs' of averting behavior influence pollution exposure.

It is also important to note that, while the Zoo is only open during the day, the Observatory is open during the day and evening, with night time visits popular for stargazing. ${ }^{13}$ Our data do not allow us to identify time of visit, so to the extent that individuals view daytime and nighttime activities at the observatory as substitutes and thus shift their outdoor activities to the night when ozone levels are substantially lower, the behavioral response to alerts measured at this location may be underestimated.

\section{B. Air Quality Information}

In accordance with the availability of attendance data, we collect air quality information from 1989-1997. The smog alert status and forecasted ozone for each of the facilities is assigned based on the 1-hour ozone forecast for the relevant AMA from the Los Angeles Times. The ozone forecast is reported in PSI units and is converted to a parts-per-million (ppm) measure, consistent with the units of measurement for observed

\footnotetext{
${ }^{10}$ A concern with using children is their responses to alerts could be a function of the state-wide rule requiring schools to reschedule outdoor activities. To address this, we perform this analysis using only days during the summer months when children are unlikely to attend school.

${ }^{11}$ Note that not while all Zoo attendees are counted in the total attendance figures, not all are broken down into these age groups because some enter as groups (such as school field trips) or under promotional packages. Of the separately identified age groups, adults make up 57 percent of all daily admissions, children 2-12 make up 28 percent, children under age 2 make up 11 percent, and seniors make up 3 percent. ${ }^{12}$ GLAZA members do not pay an admission fee per visit.

${ }^{13}$ The Zoo is open everyday from 10 a.m. to 5 p.m., with the closing time extended to 6 p.m. from July 1 to Labor Day. The Observatory is open from 2 p.m. to 10 p.m. Tuesday through Friday and 12:30 p.m. to 10 p.m. on Saturday and Sunday. When school lets out, it is open from 12:30 p.m. to 10 p.m. everyday.
} 
ozone. Since we do not have information on the AMA in which an alert is issued, we use the selection rule described in equation (1) to assign alert status. We confirm the validity of this approach by using an administrative file from SCAQMD that contains the dates that smog alerts were issued, but does not identify the AMA to which they correspond. We repeat this exercise by assigning alert status based on the maximum ozone forecast reported in the Los Angeles Times. A comparison of the two measures suggests that the selection rule is quite rigorously followed: there are only 7 inconsistencies in the 2138 data points available.

Data on frequency of alerts is also shown in Table 1. Alerts themselves are not very common events in the AMA of the Zoo and Observatory, with single day alerts occurring 5.6 percent of the time, two consecutive alerts occurring 2.3 percent of the time, and three consecutive alerts occurring 1 percent of the time. However, given the serial correlation in meteorology (and hence ozone), successive days with alerts are quite common conditional on an alert being issued the previous day. An alert was issued on the day after an alert 41 percent of the time, while an alert was issued the day after two consecutive alerts 44 percent of the time. This variation is essential for obtaining precise estimates of the impact of successive alerts.

\section{Other sources}

Time spent outdoors is likely to be influenced by weather and perhaps other air quality measures, including observed levels of ozone. To control for these confounding factors, we include measures of daily 1-hour ozone, 8-hour carbon monoxide (CO), 1hour nitrogen dioxide $\left(\mathrm{NO}_{2}\right)$, maximum temperature, precipitation, maximum relative humidity, resultant wind speed, and average sky cover from sunrise to sunset in percent 
$(0=$ clear, $1=$ overcast $)$ in our main regression specification. Pollution data are obtained from the California Air Resources Board air pollution monitoring network. ${ }^{14}$ The weather data come from surface summary of the day (TD3200), maintained by the National Climatic Data Center. ${ }^{15}$ Daily climate and air quality data are assigned to each venue using measures from the closest pollution and weather station. Means for each are also shown in Table 1.

\section{Empirical Strategy}

We begin by presenting the static model of how alerts impact attendance:

(1) $\log \left(\right.$ attendance $\left._{t}\right)=$ alert $_{t} \alpha_{0}+$ ozone $_{t}^{f} \beta_{0}+X_{t} \delta_{0}+\varepsilon_{t}$

where attendance $_{t}$ is aggregate attendance at the Zoo or Observatory on date $t$. Because the Observatory is open during the evening when ozone levels are lower and responses may be smaller than at the Zoo, we estimate this model separately for both places. alert $t_{t}$ is a dummy variable indicating whether a smog alert is issued in the AMA of the outdoor facility. ozone $e^{f}$ is the ozone forecast, which invokes the RD design. We focus on estimating a specification linear in the ozone forecast since previous evidence found that estimates are insensitive to the functional form of this variable (Neidell (forthcoming)). $X_{t}$ are potential confounding variables, including meteorological and pollution variables that affect the quality of the outdoor experience; holiday, summer schedule, and day of week dummies to account for changes in leisure time; and year-month dummy variables to account for both seasonal and temporal patterns in outdoor activities, air quality, and

\footnotetext{
${ }^{14}$ This data is available at http://www.arb.ca.gov/aqd/aqded/aqdcddld.htm.

${ }^{15}$ This data is available at http://www4.ncdc.noaa.gov/cgi-win/wwcgi.dll?wwAW MP AP. Data on humidity and sky cover are more frequently missing than the other weather variables. To prevent a loss in sample size, these missing values are imputed using a best-subset regression with the other weather variables and observed ozone as covariates. Regression results are, however, insensitive to excluding the imputed values.
} 
weather. $\varepsilon_{t}$ is an error term clustered on the ozone forecast to account for the fact that the covariate determining treatment is discrete rather than continuous (Card and Lee (forthcoming)). If $\alpha_{0}<0$, this indicates outdoor attendance decreases when alerts are announced.

To estimate the impact of two consecutive days of alerts on attendance, we expand the model as follows:

(2) $\log \left(\right.$ attendance $\left._{t}\right)=$ alert $_{t} \alpha_{0}+$ alert $_{t-1} \alpha_{1}+$ alert $_{t}^{*}$ alert $_{t-1} \alpha_{01}+$ ozone $_{t}^{f} \beta_{0}+$ ozone $_{t-1}^{f} \beta_{1}+$ $X_{t} \delta_{0}+X_{t-1} \delta_{1}+\varepsilon_{t}$

We interact contemporaneous with lagged alert to allow the impact of an alert issued today to vary depending on whether an alert was issued yesterday. ${ }^{16}$ To infer the impact of multiple day warnings, we take the derivative of (2) with respect to contemporaneous alerts: $\delta \log \left(\right.$ attendance $\left._{t}\right) / \delta$ alert $_{t}=\alpha_{0}+\operatorname{alert}_{t-1} * \alpha_{01}$. The impact on attendance of a onetime alert $\left(\right.$ alert $\left._{t-1}=0\right)$ is $\alpha_{0}$. The impact of an alert on attendance on the second day of two consecutive days of alerts $\left(\right.$ alert $\left._{t-1}=1\right)$ is $\alpha_{0}+\alpha_{01}$. This forms the basis of our main empirical tests.

Although individuals are unlikely to go to a specific outdoor venue on successive days, using aggregate responses still provides a valid test. To see this, imagine individuals have a sequence of outdoor activities for the next two days $\left\{O_{1}, O_{2}\right\}$, and do not substitute outdoor activities across days. The alternative choice on each day is an indoor activity. Individuals do not have the same ordering of activities across the two days, so some have $\{$ Zoo, Observatory $\}$ and others have $\{$ Observatory, Zoo $\}$, for example. If people respond to an alert issued on the first day, $O_{1}$ will decrease, so both

\footnotetext{
${ }^{16} X_{t-1}$ includes lags of all variables where appropriate; for example, we do not include lagged day of week dummies since this is perfectly correlated with current day of week dummies (and would result in a singular matrix).
} 
the Zoo and the Observatory experience a decline in attendance. If people do not respond to an alert issued on the second day, $\mathrm{O}_{2}$ will not change, so both the Zoo and the

Observatory experience no change in attendance. Therefore, with enough variation in the ordering of $\left\{\mathrm{O}_{1}, \mathrm{O}_{2}\right\}$ across individuals, using aggregate attendance is adequate for performing this test.

We also present a three-day model to explore the impact of a longer string of alerts:

(3) $\log \left(\right.$ attendance $\left._{t}\right)=$ alert $_{t} \alpha_{0}+$ alert $_{t-1} \alpha_{1}+$ alert $_{t-2} \alpha_{2}+$ alert $_{t} *$ alert $_{t-1} \alpha_{01}+$ alert $_{t} *$ alert $_{t-2}$

$$
\begin{aligned}
& \alpha_{02}+\text { alert }_{t-1} \text { alert }_{t-2} \alpha_{12}+\text { alert }_{t} \text { alert }_{t-1} \text { alert }_{t-2} \alpha_{012}+\text { ozone }_{t}^{f} \beta_{0}+\text { ozone }_{t-1}^{f} \beta_{1}+ \\
& \text { ozone }_{t-2}^{f} \beta_{2}+X_{t} \delta_{0}+X_{t-1} \delta_{1}+X_{t-2} \delta_{2}+\varepsilon_{t}
\end{aligned}
$$

To derive hypothesis tests comparable to above, we again take the derivative of (3) with respect to contemporaneous alerts: $\delta \log \left(\right.$ attendance $\left._{t}\right) /$ alert $_{t}=\alpha_{0}+$ alert $_{t-1} * \alpha_{01}+$ alert $_{t-}$ ${ }_{2}^{*} \alpha_{02}+$ alert $_{t-1} *$ alert $_{t-2} \alpha_{012} . \alpha_{0}$ is the impact on attendance of a one-time alert alert $_{t-1}=0$, alert $\left._{t-2}=0\right) . \alpha_{0}+\alpha_{01}+\alpha_{02}+\alpha_{012}$ is the impact of an alert on attendance on the third day of three consecutive days of alerts $\left(\right.$ alert $_{t-1}=1$, alert $\left._{t-2}=1\right)$. In this model we can also assess the impact from a one-day reprieve from smog alerts $\left(\right.$ alert $_{t-1}=0$, alert $\left._{t-2}=1\right)$ to determine the "rebound effect" $\left(\alpha_{0}+\alpha_{02}\right)$.

\section{Results}

Estimates based on equations (1) and (2) are presented in Table 2. Columns (1) and (3) present results from the static model for the Zoo and Observatory, respectively. The estimates suggest that attendance declines by 15 and 5 percent across the two facilities, with both estimates statistically significant at conventional levels. ${ }^{17}$

\footnotetext{
${ }^{17}$ Note that these estimates differ slightly from Neidell (forthcoming) because they focus on a sample without missing lagged variables.
} 
Columns (2) and (4) present results from the two-day model. Estimates of the response to an alert on the second day of two consecutive alerts falls to 5 and 0 percent across the two facilities $\left(\alpha_{0}+\alpha_{01}\right)$, respectively, neither of which is statistically significant. ${ }^{18}$ These estimates suggest that when alerts are issued on two successive days, any response on the first day has largely disappeared by the second day, suggesting individuals appear to disregard the second-day warning.

The coefficient on contemporaneous alert is unchanged for the Zoo but goes up from 5 to 8 percent for the Observatory, suggesting that the impact of a one-time alert is greater than that found in the basic static model. This is as expected because the static model averages the impact from alerts across all days regardless of previous alert status. Thus, given the diminished behavioral response on the second day of an ozone warning spell, the estimated impact from an alert in the static model must be below the estimated impact from a one-time alert in the dynamic model. Moreover, this suggests that estimates from a static model, by ignoring the dynamics of air quality, are biased, though in our specific case the bias does not appear substantial.

Table 3 presents results that explore the impact from three consecutive days with alerts. We present results from the static and two-day model again but using the same sample as the three-day model to ensure that our comparisons across models are based on the same dates. ${ }^{19}$ The results from the static and two-day model are largely unchanged from Table 2, shown in columns (1) and (2) for the Zoo and (4) and (5) for the Observatory. The response at the Zoo from three consecutive alerts $\left(\alpha_{0}+\alpha_{01}+\alpha_{02}+\right.$

\footnotetext{
${ }^{18}$ This decrease in responses from the first to second day across both facilities is statistically significant at the $5 \%$ level according to a joint test of significance when estimating the models simultaneously.

${ }^{19}$ Our sample size decreases in the three-day model because we are limiting our attention to observations that contain three lags of all time-varying covariates.
} 
$\alpha_{012}$ ) now falls to positive one percent, and is again statistically insignificant. For the Observatory, the estimate climbs somewhat to 5 percent, though it remains statistically insignificant. These estimates further support the notion of diminished responses to successive warnings.

Interestingly, we also find evidence that a short reprieve from smog alerts results in responses that rebound in magnitude to the first day response, at least for the Zoo. The response to a contemporaneous alert preceded by no alert and then an alert $\left(\alpha_{0}+\alpha_{02}\right)$ is a statistically significant 18 percent, which is comparable to the one-time only alert response of 13 percent. The magnitude of this rebound effect seems to suggest that most of the foregone utility associated with recreational abstinence on the first day of the alert was recaptured during the air quality reprieve on the second day, allowing potential visitors to reschedule activities again on the third day. The absence of such a rebound effect at the Observatory may, in part, be a reflection of a generally lower response to alerts as compared to the Zoo.

As robustness checks for our main results, we examine whether responses vary by the age and residential location of the individual, shown in Table 4. Local residents should find it easier to intertemporally substitute zoo visits and thus should exhibit a stronger response than non-locals on successive days of smog alerts. Indeed, GLAZA members, who are likely to be local residents, show a slight increase in response (though statistically insignificant) to two consecutive alerts, with the response to an alert rising from 18 to 21 percent from a one-time alert to a second consecutive alert. However, GLAZA members appear to ignore the alert on the third consecutive day of an alert spell, 
suggesting that the intertemporal costs of activity substitution are even high for local residents. The rebound effect remains prominent for this group.

We also expect more vulnerable individuals to show less of a drop off in responses since the benefits from avoiding exposure are larger for them, which is generally what we find. The most vulnerable groups -- seniors and children under 2 -display a drop off in response to a second consecutive alert that is considerably smaller than the drop off for adults. This difference becomes more pronounced when we look at the third day response, where adults show a further diminished response to the alert while seniors and young children ratchet up their response. The pattern for children 2-12 mirrors that of adults, though they are less likely to attend on any given day of a warning spell. While the lack of statistical precision in our estimated responses for each group in Table 4 limits our abilities to generate strong inferences, the pattern of results is consistent with economic theory: the response to alerts is greatest for those with the smallest costs or largest benefits associated with behavioral change.

\section{Conclusions}

Information disclosure has been touted as the new wave of environmental regulation and yet little is known about how people respond to this type of intervention. The limited knowledge we have is based on a static view of information, where individuals respond to data in a somewhat isolated fashion. At least for episodic events, this approach appears misguided. Our results reveal a response dynamic whereby behavioral changes to a smog alert depend, in part, on the prior history of such alerts. Individuals appear quite responsive to alerts on the first day they are issued, but much less so on subsequent consecutive days. Such a pattern is logical if the costs of activity 
substitution are increasing as the duration of the spell increases, but the size of the dropoff found here is surprising given the nature of the activity studied. If individuals can't seem to bear the increased costs of staying out of the zoo for two consecutive days, how might the response look for a less discretionary activity like harvesting crops or professional landscaping?

We note two potential limitations of our analysis. One, the media may decrease their efforts to publicize an alert on the later days of a string of consecutive days. While we can not verify the extent of this directly, there is one piece of evidence that suggests this is not a major concern: the rebound effect once individuals have had a day off from smog alerts. The rebound effect is nearly equal in magnitude to the impact from a onetime alert. Therefore, unless the media follows the same publicizing pattern - advertise heavily the first day, lightly the second day, heavily the third day - it seems unlikely that less media coverage can explain away the impact from two consecutive alerts.

While we maintain several notable advantages of the uniquely collected data, a second limitation concerns the generalizability of our findings: actions that occur in Southern California may not extrapolate well to other parts of the country. While we cannot directly assess this with the data used in this analysis, we note that daily outdoor time in Los Angeles County is comparable to the rest of the country. Based on computations from the American Time Use Survey (maintained by the Bureau of Labor Statistics), mean daily outdoor time in Los Angeles County is 43 minutes compare with 45 minutes elsewhere. Whether changes in outdoor time in response to external stimuli are comparable across places is unknown and beyond the scope of this paper. 
In terms of policy implications, regulators concerned about social welfare might worry about such diminished responses due to increased private costs because of the benefits associated with exposure avoidance. Smog alerts are triggered when the underlying ozone forecast index exceeds a threshold, but the ill health effects associated with ozone exposure continue to climb at concentrations above this threshold. Since individuals respond specifically to the alert but not to the underlying index itself, they appear to view the benefits associated with exposure reduction as constant with respect to the ozone forecasts that generate an alert. Whether this is due to cognitive limitations, the increased costs of uncovering the underlying index, or some sort of framing effect created by the very existence of the alert cannot be determined in our analysis.

Nonetheless, it points toward the need for more sophisticated approaches to regulation through information that embeds behavioral dynamics into decision rules to achieve welfare improving outcomes, especially as the new era of global warming makes poor air and water quality spells longer and more frequent. 


\section{References}

Ahituv, Avner, V. Joseph Hotz, and Tomas Philipson (1996). "The Responsiveness of the Demand for Condoms to the Local Prevalence of AIDS." Journal of Human Resources 31(4): 869-97.

Bresnahan, Brian, Mark Dickie, and Shelby Gerking (1997). "Averting Behavior and Urban Air Pollution." Land Economics 73: 340-357.

Card, David and David Lee (forthcoming). "Regression Discontinuity Inference with Specification Error.” Journal of Econometrics 142(2) 655-674

Environmental Protection Agency (1999). "Guidelines for Reporting of Daily Air Quality - Air Quality Index (AQI).” EPA Document \#454-R-99-010, Research Triangle Park, NC. (2006). Air Quality Criteria Document for Ozone. Washington, DC: Environmental Protection Agency.

Jin, Ginger and Philip Leslie (2003). "The Effect of Information on Product Quality: Evidence from Restaurant Hygiene Grade Cards." Quarterly Journal of Economics 118(2): 409-451.

Mullahy, John (1999). "It'll Only Hurt a Second? Microeconomic Determinants of Who Gets Flu Shots." Health Economics 8(1): 9-24.

Neidell, Matthew (forthcoming). "Information, Avoidance Behavior, and Health: The Effect of Ozone on Asthma Hospitalizations." Journal of Human Resources.

Philipson, Tomas. 1996. "Private Vaccination and Public Health: An Empirical Examination for U.S. Measles." Journal of Human Resources 31(3): 611-30

Shimshack, Jay, Michael Ward, and Timothy Beatty (2007). "Mercury Advisories: Information, Education, and Fish Consumption." Journal of Environmental Economics and Management. 53(2):158-179

Smith, V. Kerry, and Reed Johnson (1988) "How Do Risk Perceptions Respond to Information? The Case of Radon." Review of Economics and Statistics 70(1): 1-8.

Viscusi, W. Kip, Magat, Wesley A., and Huber, Joel C. (1986). "Informational Regulation of Consumer Health Risks: An Empirical Evaluation of Hazard Warnings.” RAND Journal of Economics 17(3): 351-65. 
Table 1. Summary statistics

mean std. dev.

\begin{tabular}{lcc}
\hline Alerts & & \\
Alert (\%) & 0.056 & 0.230 \\
Two consecutive alerts (\%) & 0.023 & 0.149 \\
Three consecutive alerts (\%) & 0.010 & 0.099 \\
& & \\
Attendance & & \\
\hline Zoo (n=1878) & $4,809.7$ & $3,189.5$ \\
adults & 1577.5 & 1691.4 \\
children <2 & 304.3 & 367.0 \\
children 2-12 & 780.5 & 781.2 \\
seniors & 82.3 & 51.5 \\
GLAZA members & 725.0 & 538.7 \\
Observatory (n=1554) & $5,853.1$ & $2,394.5$ \\
& & \\
Covariates & & \\
ozone 1-hour (ppm) & 0.078 & 0.038 \\
ozone 1-hour forecast (ppm) & 0.115 & 0.046 \\
maximum temperature ( $\left.{ }^{\circ} \mathrm{F}\right)$ & 82.3 & 9.7 \\
precipitation (inches) & 0.216 & 1.615 \\
relative humidity (\%) & 89.7 & 7.1 \\
average cloud cover sunrise to sunset $(\%)$ & 0.448 & 0.297 \\
resultant wind speed (mph) & 5.682 & 2.362 \\
carbon monoxide 8-hour (ppm) & 2.310 & 1.244 \\
nitrogen dioxide 1-hour (ppm) & 0.073 & 0.032 \\
\hline
\end{tabular}


Table 2. Impact of two consecutive day alerts on attendance

\begin{tabular}{lcccc} 
& 1 & 2 & 3 & 4 \\
& & Zoo & & \multicolumn{2}{c}{ Observatory } \\
\hline First day response & $-0.152^{* *}$ & $-0.154^{* *}$ & $-0.049^{*}$ & $-0.077^{* *}$ \\
$\left(\alpha_{0}\right)$ & {$[0.039]$} & {$[0.039]$} & {$[0.021]$} & {$[0.023]$} \\
Second day response & & -0.049 & & 0.002 \\
$\left(\alpha_{0}+\alpha_{01}\right)$ & & {$[0.075]$} & & {$[0.048]$} \\
Observations & 1878 & 1878 & 1554 & 1554 \\
R-squared & 0.76 & 0.77 & 0.69 & 0.69 \\
\hline
\end{tabular}

* significant at $5 \%$; ** significant at $1 \%$. Standard errors clustered on ozone forecast in brackets. $\alpha_{0}$ is the coefficient on contemporaneous alert and $\alpha_{01}$ is the coefficient on contemporaneous interacted with once lagged alerts. All regressions include an indicator for summer schedule, day of week dummies, year-month dummies. Columns 1 and 3 include contemporaneous ozone forecast, quadratic in maximum temperature, percent of sun cover, precipitation, resultant wind speed, maximum relative humidity, observed ozone, carbon monoxide, nitrogren dioxide, and an indicator for holiday; columns 2 and 4 include these same variables and alerts once lagged. 
Table 3. Impact of three consecutive day alerts on attendance

\begin{tabular}{lcccccc} 
& 1 & 2 & 3 & 4 & 5 & 6 \\
& & Zoo & & & Observatory \\
\hline First day response & $-0.155^{* *}$ & $-0.154^{* *}$ & $-0.132^{* *}$ & -0.03 & $-0.048^{*}$ & $-0.058^{*}$ \\
$\left(\alpha_{0}\right)$ & {$[0.038]$} & {$[0.040]$} & {$[0.039]$} & {$[0.021]$} & {$[0.020]$} & {$[0.025]$} \\
Second day response & & -0.063 & -0.124 & & 0.001 & 0.052 \\
$\left(\alpha_{0}+\alpha_{01}\right)$ & & {$[0.069]$} & {$[0.062]$} & & {$[0.050]$} & {$[0.056]$} \\
Third day response & & & 0.011 & & & -0.046 \\
$\left(\alpha_{0}+\alpha_{01}+\alpha_{02}+\alpha_{012}\right)$ & & & {$[0.106]$} & & & {$[0.062]$} \\
Rebound effect & & & $-0.182^{*}$ & & & 0.052 \\
$\left(\alpha_{0}+\alpha_{02}\right)$ & & & {$[0.089]$} & & & {$[0.071]$} \\
Observations & 1809 & 1809 & 1809 & 1347 & 1347 & 1347 \\
R-squared & 0.77 & 0.78 & 0.78 & 0.66 & 0.67 & 0.67 \\
\hline
\end{tabular}

* significant at $5 \%$; ** significant at $1 \%$. Standard errors clustered on ozone forecast in brackets. $\alpha_{0}$ is the coefficient on contemporaneous alert, $\alpha_{\mathrm{ij}}$ is the coefficient on alerts lagged i time interacted with alerts lagged $\mathrm{j}$ times, and $\alpha_{012}$ is the coefficient on contemporaneous interacted with once and twice lagged alerts. All regressions include an indicator for summer schedule, day of week dummies, year-month dummies. Columns 1 and 4 include contemporaneous ozone forecast, quadratic in maximum temperature, percent of sun cover, precipitation, resultant wind speed, maximum relative humidity, observed ozone, carbon monoxide, nitrogren dioxide, and an indicator for holiday; columns 2 and 5 include these same variables and alerts once lagged; columns 3 and 6 include these same variables and alerts twice lagged as well as all pairwise interaction between contemporaneous, once lagged, and twice lagged alerts. 
Table 4. Impact of consecutive day alerts on attendance by demographic (Zoo only)

\begin{tabular}{cccccc} 
& 1 & 2 & 3 & 4 & 5 \\
& GLAZA & Adults & Seniors & $\begin{array}{c}4 \\
\text { Children 2- } \\
12\end{array}$ & $\begin{array}{c}\text { Children }< \\
2\end{array}$ \\
\hline First day response & $-0.178^{* *}$ & $-0.140^{* *}$ & $-0.143^{*}$ & $-0.207^{* *}$ & $-0.148^{*}$ \\
$\left(\alpha_{0}\right)$ & {$[0.054]$} & {$[0.042]$} & {$[0.062]$} & {$[0.043]$} & {$[0.061]$} \\
Second day response & -0.212 & -0.074 & -0.092 & -0.090 & -0.115 \\
$\left(\alpha_{0}+\alpha_{01}\right)$ & {$[0.124]$} & 0.065 & {$[0.073]$} & {$[0.108]$} & {$[0.139]$} \\
Third day response & 0.046 & -0.045 & -0.148 & -0.072 & $-0.339^{* *}$ \\
$\left(\alpha_{0}+\alpha_{01}+\alpha_{02}+\alpha_{012}\right)$ & {$[0.158]$} & 0.127 & {$[0.129]$} & {$[0.179]$} & {$[0.125]$} \\
Rebound effect & $-0.257^{*}$ & $-0.217 *$ & $-0.274^{* *}$ & $-0.349^{* *}$ & -0.172 \\
$\left(\alpha_{0}+\alpha_{02}\right)$ & {$[0.120]$} & {$[0.088]$} & {$[0.083]$} & {$[0.137]$} & {$[0.169]$} \\
Observations & 1804 & 1809 & 1806 & 1805 & 1804 \\
R-squared & 0.66 & 0.87 & 0.69 & 0.81 & 0.72 \\
\hline
\end{tabular}

* significant at $5 \%$; ** significant at $1 \%$. Standard errors clustered on ozone forecast in brackets. $\alpha_{0}$ is the coefficient on contemporaneous alert, $\alpha_{\mathrm{ijj}}$ is the coefficient on alerts lagged $i$ time interacted with alerts lagged $j$ times, and $\alpha_{012}$ is the coefficient on contemporaneous interacted with once and twice lagged alerts. All regressions include an indicator for summer schedule, day of week dummies, year-month dummies. All regressions include contemporaneous, once lagged, and twice lagged ozone forecast, quadratic in maximum temperature, percent of sun cover, precipitation, resultant wind speed, maximum relative humidity, observed ozone, carbon monoxide, nitrogren dioxide, and an indicator for holiday, as well as once and twice lagged alerts. 